\title{
Da conciliação trabalhista à resistência brizolista: o Partido Trabalhista Brasileiro (PTB) na região Oeste de Santa Catarina (1950-1965)
}

From the labor conciliation to the brizolist resistance: the Brazilian Labor Party (PTB) in the western region of Santa Catarina (1950-1965)

Claiton Marcio da Silva*

Carla Aparecida Rigo ${ }^{\star *}$

Palavras-chave:

Leonel Brizola

Brizolismo

Grupo dos Onze Companheiros

Keywords:

Leonel Brizola

Brizolismo

Grupo dos Onze Companheiros

\begin{abstract}
Resumo: O presente trabalho tem por objetivo analisar o surgimento da influência de Leonel de Moura Brizola na política de Chapecó/SC entre 1950 e 1965. Neste sentido, este artigo aborda o período compreendido entre o surgimento do Partido Trabalhista Brasileiro (PTB) e sua atuação conciliadora ao longo da década de 1950, até o crescimento da influência de Brizola em nível nacional enquanto um dos símbolos da resistência política através da "Campanha da Legalidade" e a criação do "Grupo dos Onze Companheiros". A violência - física ou simbólica - é o fio condutor desta narrativa, argumentando como a história política local foi permeada pela perseguição aos grupos trabalhistas - também considerados "comunistas" por parte de grupos conservadores. Se em 1950 a influência conciliadora de Getúlio Vargas (pós-Estado Novo) ou de Alberto Pasqualini forneceu a linha do partido, ao final daquela década, uma nova geração de jovens na região Oeste de Santa Catarina adentrou na vida política tendo Brizola - e seus "admiráveis discursos", que alcançavam a região através da rádio - como referência.
\end{abstract}

Abstract: It aims to discuss the rising influence of Leonel de Moura Brizola over the Labor Party (PTB) in Chapecó, Santa Catarina, between 1950 and 1965. In this perspective, this article discusses the political process since the party's early conciliatory position during 1950s until the rising of Brizola's as a symbol of political resistance in the national level through the "Campanha da Legalidade" and the creation of the "Grupo dos Onze Companheiros". The symbolic and physical violence is the central argument of the narrative, demonstrating this persecution to the trabalhistas in the local political history. If Pasqualini or Getúlio Vargas' conciliatory influence (in 1950, post-Estado Novo) provided the main ideal for the PTB, at the end of that decade, a new generation of young politicians was created in the Western of Santa Catarina, following Leonel Brizola as a leader - having his radio speeches as the main political reference.

\section{Introdução: PTB, brizolismo e o Oeste Catarinense}

Este trabalho tem por objetivo principal abordar a trajetória do Partido Trabalhista Brasileiro por intermédio da crescente influência de Leonel de Moura Brizola (1922-2004) sobre a política chapecoense e regional. Conhecido reduto Brizolista, onde o candidato a Presidente pelo
Partido Democrático Trabalhista (PDT) venceu localmente as eleições de 1989, observamos que não existem estudos que marcam o surgimento da influência desta liderança oriunda do Rio Grande do Sul em terras catarinenses. Dessa forma, este trabalho pretende discutir como, entre diferentes projetos políticos e destacadas lideranças do Partido Trabalhista Brasileiro (PTB) - como Getúlio Vargas, João Goulart e Alberto Pasqualini - o então jovem

\footnotetext{
* Doutor em História pela Casa de Oswaldo Cruz, COC/Fiocruz. Professor Associado na Universidade Federal da Fronteira Sul. Professor do Curso de Mestrado em História e de História da Fronteira Sul. E-mail: <claiton@uffs.edu.br>.

** Mestre em História pela Universidade do Centro-Oeste do Paraná (Unicentro). E-mail: <karla-rigo@hotmail.com>
} 
Leonel Brizola construiu um papel de destaque que ecoou para a região Oeste de Santa Catarina. Isto explica, ao menos em parte, como o brizolismo permaneceu durante décadas como uma importante tradição política, mais conhecida e influente que a própria tradição de Getúlio ou Jango nesta região.

O brizolismo, como tradição de pensamento político, é assunto que embora não esgotado, foi estudado por um grande número de pesquisadores (SZATKOSKI, 2008; RIGHI, 2014; BRANDALISE; HARRES, 2014). No entanto, o surgimento de Leonel Brizola enquanto liderança "acima” dos partidos políticos se constitui como um importante fenômeno para política regional. O diálogo com as obras de Hass (2001, 2007), Silva (2014) e Siqueira (2016), que abordam aspectos da formação política regional após a Segunda Guerra Mundial, fornecem elementos para, por outro lado, abordar o PTB local e o brizolismo como um fenômeno singular. Em outras palavras, a ascensão de Leonel Brizola como liderança significou um rompimento com uma tradição muito influente na década de 1950, ou seja, a da conciliação; e seguiu como forma de resistência quando da criação do Partido Democrático Trabalhista (PDT), já no final da civilditadura militar (1964-1985). Um dos pontos em comum entre esta narrativa e os livros mencionados é a permanência tanto de violência física quanto simbólica como elemento fundante e fundamental para a história política regional.

Nesse sentido, o pensamento político-social conhecido como brizolismo foi construído sob uma aura de resistência à violência tanto em nível nacional quanto local. O estudo de Hass (2007) sobre o linchamento ocorrido em Chapecó em outubro de 1950 marcou o início de uma abordagem que relaciona os fenômenos sociais aos elementos políticos, pouco presente na memória social. Mais especificamente, se o entendimento sobre o linchamento - mediante esta referida memória social regional - foi interpretado enquanto uma atitude isolada protagonizada por determinados atores em um ato "irracional", Hass demonstra que tanto o responsável pela organização do linchamento quanto as vítimas tinham um posicionamento partidário evidente, e neste caso, oposto.
De certa forma, se a violência era um aspecto bastante conhecido nos sertões catarinense desde a década de 1920, o episódio do linchamento inaugurou um processo de perseguição sobre simpatizantes ou membros do PTB que, embora tenha sido descompassado ao longo dos anos 1950, encontrou seu momento mais tenso na primeira metade da década de 1960, com o golpe civil-militar de 1964.

Em termos de produção bibliográfica, ao estudo sobre o linchamento seguiu-se a dissertação de mestrado transformada em livro posteriormente sobre as elites políticas chapecoenses (HASS, 2001). Neste estudo, Monica Hass aborda o período pluripartidário, argumentando como o linchamento produziu uma nova organização das elites locais, tendo em vista que o modelo econômico representado pela indústria madeireira se encontrava em fase de esgotamento. A década de 1950 produziu a rearticulação das disputas locais com a instalação da agroindústria no município, promovendo uma onda de desenvolvimento econômico e estimulando uma nova configuração das alianças políticas.

Posteriormente, o estudo de Silva (2014) retomou alguns dos argumentos de Hass e buscou aprofundar a pesquisa no período bipartidário (1965-1979) em Chapecó, arranjo criado pela ditadura civil-militar para facilitar o controle do processo político.. O livro em questão abordou o impacto do golpe civil-militar em nível local, e a reconfiguração dos partidos e das alianças entre as elites, visando à manutenção do controle político; também, abordou os conflitos diante do surgimento de novas lideranças trabalhistas (PTB). Em uma sociedade que relativamente se industrializava e se urbanizava, a política local chapecoense se tornava mais complexa no sentido que novos grupos sociais ascendiam à disputa eleitoral. Dessa forma, se antes os madeireiros, comerciantes, industriais e colonizadores dominavam a cena, os bacharéis e os grupos de lideranças mais jovens marcavam presença, principalmente na oposição à ditadura. Foi neste contexto que o então prefeito Sadi José de Marco (ex-PTB) se tornou o epicentro de diversas 
disputas de poder, concluindo com sua cassação através do Ato Institucional no 5 em abril de 1969.

O trabalho de Siqueira (2016) buscou renovar a abordagem da história política local com a análise da atuação das lideranças pela teoria de redes. Analisando a composição do quadro político local no período pluripartidário e bipartidário, Siqueira, observando os representantes chapecoenses nas câmaras estadual e federal, percebeu uma aproximação dos diferentes partidos e projetos em torno de duas grandes lideranças locais: Serafim Enoss Bertaso e Plínio Arlindo de Nês, ambos filiados ao PSD e, posteriormente, à Aliança Renovadora Nacional (ARENA). O primeiro continuou sendo o principal representante do período coronelista; o segundo, por sua vez, foi um dos responsáveis pela introdução de uma complexa rede agroindustrial que se expandiu nas décadas seguintes. Os espaços públicos e privados, nesse sentido, mais do que distanciar os atores, serviu também como elemento de aproximação das elites políticas para a construção de consensos sobre os projetos de desenvolvimento local.

A continuidade que este trabalho oferece no diálogo com os demais é justamente, como afirmamos, a abordagem da política local enquanto um exercício contínuo de diferentes formas de violência (MUCHEMBLED, 2012; MARCONDES FILHO, 2001; COIMBRA, 2001; CARVALHO, 2010; ALVES, 2005; BRASIL, 1997). Logo, este estudo se referencia entre dois grandes eventos pautados pela violência: o linchamento ocorrido em Chapecó em 1950 e a prisão política de membros e simpatizantes do PTB nos dias que se seguiram ao golpe civilmilitar de 1964. Em comum, estes dois episódios de violência - assim como outros que ocorreram posteriormente, no contexto do AI-5 - foram cometidos contra simpatizantes e membros do PTB, em menor número no linchamento, onde apenas um dos acusados era filiado ao partido, e em maior número nas prisões de 1964.O final do Estado Novo (1937-1945) marca a inserção do trabalhismo na política chapecoense por meio de uma orientação política cristã e conciliadora, baseada, sobretudo em características do pensamento de Getúlio Vargas e, com maior força, a partir de Alberto Pasqualini.
A certa altura - entre o final da década de 1950 e o início dos anos 1960 - Leonel Brizola, ganhou força ao promover a Campanha pela Legalidade, com discursos "aguerridos" dirigidos contra as elites que não desejavam a posse de Jango; conquistou uma série de admiradores em diversas regiões do país, inclusive na região de Chapecó. Outras lideranças petebistas - como Doutel de Andrade - eram frequentemente mencionadas como influência pelos jovens locais; por outro lado, a influência do jovem político gaúcho foi fundamental. E como resultado, a ascensão de Brizola como líder político modificou a forma de atuação do PTB local - considerado até então como moderado - para uma postura que, pouco mais tarde, às vésperas do golpe civil-militar, veio a ser chamada de "comunista".

Dentro das correntes internas do PTB, existiam os "doutrinários trabalhistas", ou seja, os "intelectuais orgânicos" do partido. Esta tendência tinha uma orientação trabalhista considerada socializante, e suas principais características eram o nacionalismo, proximidade à social democracia, assim como a "[...] contraposição ao comunismo, maior identidade com o socialismo reformista, independência em relação ao aparelho burocrático do Estado e a projetos personalistas de quaisquer líderes políticos" (CRUZ, 2010, p. 46). Destacaramse nesta tendência, Alberto Pasqualini, Fernando Ferrari, Sérgio Magalhães e Santiago Dantas. Por outro lado, os "pragmáticos reformistas" buscavam promover

Uma concepção paternalista no tocante às políticas sociais, ora protagonistas de uma nova linha de ação trabalhista - que incorporou questões como distributivismo e justiça social -, bebiam ao mesmo tempo das fontes do getulismo e do trabalhismo doutrinário. O político gaúcho Leonel Brizola e o sindicalista mineiro Clodsmidt Riani foram outros dois expoentes da tendência. (CRUZ, 2010, p. 46).

O brizolismo, como conceito, já foi utilizado enquanto "ideologia" por autores como Szatkoski (2003). Esta autora lembra que a ideologia brizolista teria surgido principalmente 
com a publicação do Jornal "O Panfleto" em 1964. De forma complementar, para este estudo, nos referimos ao brizolismo como pensamento voltado ao nacionalismo anti-imperialista, crítico à política externa dos Estados Unidos para a América Latina, seu projeto de desenvolvimento nacional e a postura "intransigente", "aguerrida", em pronunciamentos e na defesa das "questões sociais". Tais características são observadas no trabalho de Igor Grill (2005, p. 532), que aponta como características de Brizola: a sua capacidade de "comunicação com as massas", a sua "competência administrativa", além do cunho social e nacionalista dos programas que desenvolveu. Também, se faz necessário mencionar a ligação pessoal com Getúlio Vargas e o vínculo familiar com João Goulart (por meio do casamento com uma de suas irmãs)" (GRILL, 2005, p. 532).

Brizola aumentou sua inserção política em um contexto de disputa tanto com os setores conservadores quanto pela liderança de centroesquerda no PTB. De acordo com Motta, no início dos anos 1960, as posturas consideradas radicais de Brizola teriam contribuído para a elevação da "temperatura" política. Ocupando uma vaga na Câmara dos Deputados, Brizola teria se tornado um dos principais expoentes do lema "reformas na lei ou na marra". Em determinada ocasião, falando em um evento em Natal, teria feito "[...] uma provocação pessoal ao Comandante local do Exército, o General Antônio Carlos Muricy, episódio que quase degenerou em violência" (MOTTA, 2000, p. 290).

Diante do exposto, Leonel Brizola, admirado por alguns e criticado por outros, teve influência marcante em diversas regiões do Brasil, incluindo a região de Chapecó. Para isso, observaremos como a tradição Brizolista ganhou espaço no contexto político local/nacional entre 1950 e 1965.

\section{O Oeste Catarinense: quando o trabalhismo se encontra com os ecos do mandonismo político local}

Em 1946, um artigo da Revista do Globo especulou as diferentes interpretações sobre os ideários de Alberto Pasqualini, forte liderança petebista à época:
UM OPERÁRIO: "O dr. Alberto Pasqualini é amigo dos pobres como o dr. Getúlio. Se ele fizer no governo do Rio Grande do Sul o que me disseram que está prometendo, os trabalhadores só terão a lucrar. Eu sou militante do PTB e vou votar em Alberto Pasqualini, o candidato do senador Vargas. "UM FUNCIONÁRIO: "Conheço o dr. Pasqualini apenas através desses retratos pregados na rua. Não tenho nada contra e acho até que vou votar nele, só para me divertir, para ver de que jeito ele botará na prática seu programa verdadeiramente utópico. No fim de três meses, ele pedirá demissão [...]”. UM INDUSTRIALISTA: "Pasqualini é o meu candidato ao governo do Rio Grande do Sul. Eu votaria nele mesmo que a sua candidatura não tivesse $o$ apoio do Getúlio. É um homem moço e um bom democrata. É inteligente e bem-intencionado. Mas, se ele for apoiado pelos comunistas, não quero nada com ele". (CRUZ, 2010, p. 12).

Ao simular um diálogo entre três setores diferentes da sociedade - operários, funcionários e industrialistas - observamos que a suposta afirmação dos últimos expõe claramente a tendência seguida nas décadas seguintes em relação ao petebismo. Primeiramente, a tradição getulista aproximava os diferentes grupos políticos; no entanto, como sublinhado na última frase da referência, "se ele for apoiado pelos comunistas, não quero nada com ele", delineou que, caso os comunistas dialogassem com Pasqualini, este receberia apoio diminuto. Aos poucos, com o retorno de Vargas à presidência pelo voto direto em 1950, uma forte campanha voltada ao crescimento do trabalhismo ganhou força. Grande parte da retórica política conservadora, neste momento, concentrou-se no anticomunismo crescente em tempos de Guerra Fria. Com isso, a chegada do trabalhismo petebista nas regiões interioranas, embora com tendência cristã/católica, foi geralmente associada ao comunismo. E conforme a temperatura anticomunista no Brasil aumentava, maior era a repressão aos petebistas.

Em nível local, entre 1950 e a metade dos anos 1960 , podemos observar que vários conflitos políticos culminaram com exercício repressivo 
aos membros do PTB: o linchamento de 1950, a perseguição ao Grupo dos Onze Companheiros e a prisão de filiados ao PTB durante o golpe civilmilitar em abril de 1964.

Nesta linha, em Chapecó, o início de tal repressão foi marcado com a eleição de outubro de 1950, quando os trabalhistas conquistaram a prefeitura municipal. $\mathrm{O}$ processo de interiorização do petebismo/trabalhismo encontrou em Chapecó um contexto de mandonismo político denso, com ecos do sistema coronelista, dificultando a organização e atuação de grupos políticos urbano/ industriais. Entre 1917 e 1931 o mandonismo na região tinha por base o poder econômico madeireiro/ervateiro, e por característica, proteção aos amigos, perseguição a adversários políticos, ataques a imprensa, destinação de cargos públicos, coações e até mesmo assassinatos. A partir do processo de colonização oficial, esse poder passou a ser controlado pelas Companhias Colonizadoras (HASS, 2007).

A década de 1920 foi um período de intensos conflitos entre os coronéis locais, devido principalmente à disputa pelo comércio da ervamate e controle político dos moradores; também, existia resistência a chegada de migrantes/colonos, oriundos do estado do Rio Grande do Sul (HASS, 2007 , p. 40). Com o aumento da produção de ervamate na região, promovendo relativo crescimento econômico, muitas famílias se instalaram em Santa Catarina, ocasionando o aumento das disputas pela propriedade das terras (BRANDT; SILVA, 2014, p. 459). Para contornar a situação desfavorável entre os migrantes, o governo estadual nomeou um sócio da colonizadora Bertaso, o Coronel Manoel dos Santos Maia, como delegado da polícia. E, de acordo com o pensamento conservador predominante, “[...] coube a ele cuidar da ordem pública, uma vez que era responsabilidade dos colonizadores trazerem a ordem e consequentemente, o progresso para a região" (HASS, 2007, p. 40).

Nas décadas de 1930 e 1940, tendo as Companhias Colonizadoras se consolidado enquanto camada predominante da elite local contando com o apoio da Igreja Católica - este modelo de desenvolvimento da regional começou a alcançar outros setores, propiciando um crescimento do comércio e da indústria, além da extração da madeira e erva-mate. Contudo, outro fator que causou transformação no setor político, em específico na cidade de Chapecó, foi a criação de partidos políticos, contando com sete siglas partidárias após 1946: o Partido Social Democrático (PSD), União Democrática Nacional (UDN), Partido Trabalhista Brasileiro (PTB), Partido de Representação Popular (PRP), Partido Social Progressista (PSP), Partido Libertador (PL) e o PDC, Partido Democrático Cristão (HASS, 2007, p. 50).

Apesar do quadro político alterado, o velho coronelismo continuou presente na região, formado principalmente por colonizadores e madeireiros. Mas:

A entrada de novos elementos na configuração o poder político chapecoense não se deu de forma pacífica, acarretando um período de muita violência. A disputa pelo poder de mando local, no início dessa fase de transição, foi marcada por acirrados conflitos político-partidários, caracterizados por perseguição a adversários políticos (com demissões, transferências e assassinatos), por coação ao eleitorado, por denúncias de corrupção e desmandos administrativos. (HASS, 2007, p. 50).

Evidencia-se neste momento que a criação de novas siglas partidárias aumentou as tensões políticas. A "educação moral" e os valores de trabalho e religião não foram suficientes para acomodar os interesses políticos divergentes que surgiam neste novo contexto após a deposição de Getúlio Vargas em 1945. Cabe lembrar que os Bertaso, ligados ao PSD, promoveram a vinda de mais de 8 mil famílias do Rio Grande do Sul para Santa Catarina (HASS, 2007, p. 40). Por outro lado, nesse processo de mudanças econômicas e políticas em nível nacional e regional, com muitos estudantes frequentando escolas ou universidades no Rio Grande do Sul, as ideias que estavam em evidência do Estado vizinho foram adaptadas na região Oeste. Um destes "novos" aspectos era o ideal urbanotrabalhista, notadamente através da influência de Getúlio Vargas e de Pasqualini. 
Os conflitos políticos atingiram um primeiro e dramático ápice com o incêndio da igreja e o linchamento de quatro acusados em 1950. Conforme destaca Hass (2007, p. 53), o linchamento foi, de certa forma, uma espécie de acerto político devido às eleições terem modificado o cenário local. Cabe salientar que as primeiras narrativas sobre o acontecimento apontavam para a versão que os prisioneiros foram linchados por utilizaremse continuamente da estratégia de atear fogo em determinados locais da cidade para, aproveitandose da distração dos moradores, furtar residências e comércios. A população, de acordo com esta versão, revoltou-se ainda mais com o incêndio na Igreja Católica, fato que motivou tal crime (HASS, 2007, p. 53).

Em nível político-partidário, o PSD perdeu as eleições municipais daquele ano para o $\mathrm{PTB}$, o que gerou uma série de conflitos. Com a ascensão de uma nova classe urbano-industrial ligada principalmente ao PTB e à UDN, o poder local dividiu-se entre estes dois partidos e o PSD, gerando novas alianças locais e estaduais como forma de conquista ou manutenção da dominação. Se para a eleição de 1950 o PTB e a UDN estavam aliados para a disputa eleitoral, a tendência ao longo da década foi de afastamento por parte dos dois partidos, principalmente após a forte oposição realizada por Carlos Lacerda contra o governo de Getúlio Vargas (SIQUEIRA, 2016).

E como principal consequência de 1950, a continuidade do projeto colonizador se daria, daquele momento em diante, pela substituição do modelo madeireiro pela estruturação da agroindústria no município. Reunidas em torno de um projeto comum, ou seja, recuperar a economia por meio da agroindústria, as disputas durante a década de 1950 destacaram figuras conciliadoras oriundas do PTB como os prefeitos José de Miranda Ramos (1950) e Thucydides Paim Butuhy (1954) (SIQUEIRA, 2016, p. 57). Posteriormente, Plínio Arlindo de Nês assumiu a prefeitura, devolvendo ao PSD o controle municipal após dois mandatos do PTB. Porém, cabe destacar que a vitória do PSD apenas foi possível com o apoio do PTB naquelas eleições. Mesmo com as resistências iniciais junto ao PTB por parte do PSD
- maioria da câmara de vereadores naquela gestão de Miranda Ramos - aos pouco as duas siglas se aproximaram devido aos acordos em nível estadual, que colocavam PSD e PTB lado a lado para conter o avanço da UDN (SILVA, 2014) no início dos anos 1960 pela Aliança Social Trabalhista (AST). Como perfil predominante, o PTB apresentou ao longo da década de 1950, lideranças moderadas como o comerciário João Destri (SILVA, 2014), eleito pelo PTB em 1960.

Dessa forma, evidenciou-se "[...] que a violência característica pela disputa do poder na região oeste vai diminuindo a partir das possibilidades de dominação institucional" (SIQUEIRA, 2016, p. 63). No entanto, com o final da década se aproximando, a Revolução Cubana de 1959, a Guerra Fria e os conflitos internos em torno da oposição ao governo de Juscelino Kubitschek modificariam o perfil dos "novos" petebistas da região. Estudantes de Direito em Passo Fundo, Porto Alegre ou Curitiba, como Sadi José de Marco, Genir Destri (filho de João Destri), entre outros, trouxeram uma nova perspectiva de atuação política, conflitando com a postura conciliadora. Por isso, abordaremos como a construção de uma postura política menos conciliatória, de centro-esquerda se tornou o sistema de resistência mais efetivo na conquista de adeptos frente à tentativa de golpe em 1961 e ao golpe civil-militar de 1964. Também, observaremos a chegada destas proposições em nível local: se por um lado, para alguns, Leonel Brizola representava a resistência "aguerrida" através de seus pronunciamentos e atitudes, por outro, o anticomunismo se fez presente em nível local, acirrando as disputas regionais.

\section{Da Campanha da legalidade à ditadura civil-militar: o brizolismo como resistência (1961-1964)}

Em Santa Catarina, em especial Chapecó, o discurso anticomunista foi propagado fundamentalmente pelos udenistas, através da imprensa. Com a aliança entre PTB, PSD e PCB, a UDN passou a aumentar o tom das acusações de que os pessedistas também eram comunistas ${ }^{1}$. A partir 
da década de 1950, o anticomunismo ganhou força em todo o território nacional, muito em função da resistência das elites civis e militares em relação à posse de João Goulart. A Campanha da Legalidade de 1961, que teve Brizola como líder durante seu mandato como governador do Rio Grande do Sul (1959-1963), também foi vista como uma estratégia “comunista” (MONTEIRO, 2011, p. 25).

Neste contexto, a Campanha da Legalidade surgiu e se concentrou principalmente no Rio Grande do Sul, com foco na capital gaúcha Porto Alegre, mas o movimento também adentrou outras regiões do estado, como Passo Fundo ${ }^{2}$.

Na região Oeste de Santa Catarina e no Alto Uruguai gaúcho, a campanha difundiu-se principalmente por rádio - e pela influência cultural de migrantes oriundos do Rio Grande do Sul. O movimento alcançou cidades geograficamente próximas a Chapecó - Passo Fundo, Erechim e Nonoai - e o nome de Leonel de Moura Brizola difundiu-se ainda mais pelo interior do estado. Nesse contexto, o então estudante de Direito, Genir José Destri, resumiu sua experiência de formação política diante da situação política nacional e regional:

[...] são origens trabalhistas que eu tenho desde o getulismo, porque já no governo, e mesmo na ditadura de Getúlio, acompanhava em 1944, 1945, a gente acompanhava pela $\mathrm{Voz}$ do Brasil o desfecho do governo, em 1946 teve a redemocratização com a eleição do governo de Eurico Gaspar Dutra, e depuseram o presidente Getúlio Vargas. Mas depois teve o movimento do próprio povo, as forças políticas foram buscar o Getúlio Vargas de volta para a sua eleição em 1950 para presidente da república através do "golpe democrático", foram buscá-lo em São Borja, e eu era um garoto, estudante de ginásio e já me empolguei e entrei [...] isso lá em Joaçaba como estudante de ginásio, e a partir daí fui para Porto Alegre, estudei no colégio Rosário, e ali ampliei um pouco mais as minhas bases trabalhistas através da doutrina de Pasqualini, e Getúlio, João Goulart, [e posteriormente] Brizola, naquela época tinha gente em todo esse movimento. (DESTRI, 1999).
De atuação política moderada, ao menos no início da década de 1960, Genir Destri elegeuse vereador em Chapecó, presidiu o partido e foi deputado estadual durante aquela década, até ser cassado pelo Ato Institucional $\mathrm{n}^{\circ} 5$ em 1969. Buscando demonstrar suas origens políticas e a admiração pelo trabalhismo desde os tempos de Getúlio Vargas, e manifestar certa empolgação com os movimentos políticos que aconteceram ao longo da década de 1950, Genir Destri mencionou as influências políticas desde Vargas e Pascoalini até Jango e Leonel Brizola. Assim como Destri, o vereador durante a década de 1960 e vice-prefeito no início dos anos 1970, Ferdinando Damo, e o prefeito de Chapecó cassado pelo regime civilmilitar em 1969, Sadi José de Marco, apresentam um perfil semelhante - embora tivessem disputado por diversas vezes a liderança do PTB local: todos com idade menor de 25 anos quando eleitos pela primeira vez; estudantes de Direito no Rio Grande do Sul em período próximo à Campanha da Legalidade; e, por fim, reconhecidos pela "garra" de seus pronunciamentos públicos ${ }^{3}$.

Essa postura semelhante à linha de ação Brizolista marcou a trajetória de Sadi José de Marco. Reconhecido na imprensa local por pronunciamentos considerados "vibrantes" e "provocativos", De Marco também seguiu a linha traçada por outros integrantes do PTB, com laços políticos atrelados a Getúlio, Pasqualini, Jango e Brizola, assim como mais tarde, por Doutel de Andrade. Além disso, em sua administração como prefeito de Chapecó (1966-1969), a atuação política lembrava, em suas próprias palavras, algumas das bandeiras de Leonel Brizola, como um forte investimento na construção de escolas. Também, De Marco era considerado oposição ao Governo Federal, muito em função de seus discursos e declarações públicas, na qual cobrava investimentos para o município (SILVA, 2014, p. 76).

A Campanha da Legalidade, dessa forma, enquanto movimento nacional e com forte interiorização no Rio Grande do Sule Santa Catarina, alcançou a região de Chapecó e abriu espaço para a linha Brizolista. E este movimento, somado a outros fatores, produziu uma nova geração de políticos 
voltados para a pauta das chamadas "questões sociais", identificada com fortes pronunciamentos - uma das "marcas registradas" de Leonel Brizola. Com isso, se ainda não é possível afirmar sobre a existência de um brizolismo stricto sensu no início dos anos 1960, por outro lado, observamse elementos que caracterizavam a simbologia política de Brizola. A crescente influência desta forma de ação política - análoga ao brizolismo - intensificou-se sobre os jovens políticos em um contexto de crescente anticomunismo; e os eventos relacionados ao golpe civil-militar de 1964 deixaram esta influência ainda mais evidente, principalmente através do debate que envolve a criação e atuação do "Grupo dos Onze Companheiros" - ideia atribuída a Leonel Brizola. Por conseguinte, os jovens petebistas se distanciavam, cada vez mais, de uma posição conciliadora tal qual a de Pasqualini; e se aproximavam cada vez mais das características do Brizolismo às portas do golpe de 1964.

\section{O golpe civil-militar e o Grupo dos Onze: repressão ao brizolismo e aos movimentos de resistência}

Após a Campanha da Legalidade e o crescente anticomunismo que resultaria no golpe civil-militar de 1964, atribui-se a Leonel Brizola a criação de uma organização de resistência conhecida como o "Grupo dos Onze Companheiros", "Grupo dos Onze" ou "Comando Nacionalista" (CN). Em período posterior ao golpe, o Grupo dos Onze avançou em termos de adesão social, contando com outros líderes políticos, por exemplo, Ney Ortiz Borges, getulista e integrante da Ala Moça do PTB, vereador em Porto Alegre, líder do PTB na câmara de vereadores e deputado federal em 1962 (BRANDALISE; HARRES, 2014, p. 68). O novo grupo, no entanto, não se restringiu apenas ao PTB:

A maior concentração dos Grupos foi no interior do Rio Grande do Sul, por dois motivos em especiais: o sucesso da Campanha da Legalidade que projetou Brizola como líder nacional e reforçou ainda mais seu prestígio entre os gaúchos por sua administração bem-sucedida como governador (1959-1963) e por privilegiar a luta pela reforma agrária. Neste momento Leonel de Moura Brizola tornava-se, gradualmente, o líder das esquerdas no Brasil, seu perfil de liderança agregava os grupos e concentrava seus objetivos, além de sua facilidade de mobilização das massas. (RIGHI, 2014, p. 4).

O grupo tinha como objetivo principal formar uma frente de resistência em torno da continuidade do governo de João Goulart - e da defesa das reformas de base, principalmente a reforma agrária e urbana (ZONATTO, 2010, p. 23). Mas, para além das reformas de base, os membros do grupo tinham como intuito organizar um movimento de massa fundamentado na ideologia do nacionalismo popular revolucionário. Em um segundo momento, passou-se a pensar na composição de um partido revolucionário, o qual, na opinião de alguns autores, seria indispensável para Leonel Brizola (RIGHI, 2014, p. 2).

O processo de perseguição aos Brizolistas em Chapecó e região, organizados ou não por meio do Grupo dos Onze Companheiros, alcançou seu ponto máximo nos anos iniciais da ditadura civilmilitar. A ideia proposta por Brizola para resistir ao golpe civil-militar de 1964 chegou à região no contexto das tensões políticas; nos primeiros dias do mês de abril de 1964, um grande processo de repressão fora instaurado sobre os membros do PTB em várias cidades da região Oeste de Santa Catarina e Rio Grande do Sul, conduzindo-os à prisão ou a interrogatórios. O relatório da Comissão da Verdade Paulo Stuart Wright de 2014 - referência ao deputado estadual cassado e assassinado durante a ditadura - mapeou os relatos de violações de direitos humanos, apontou a repressão em diversas cidades catarinense e evidenciou a perseguição aos brizolistas:

As violações no meio rural aconteceram em função da organização dos chamados Grupo dos Onze, brizolistas que pretendiam se organizar para defender o governo de João Goulart. Mais de duzentos catarinenses foram presos em 1964, acusados de 
pertencerem ao Grupo dos Onze. As cidades que mais sofreram este tipo de repressão situam-se no oeste do Estado catarinense, área de pequenas propriedades agrícolas. Foram todas prisões ilegais, sem ordem judicial em: Araquari, Caçador, Campos Novos, Caxambu do Sul, Chapecó, Dionísio Cerqueira, Irineópolis, Ituporanga, Joaçaba, Lages, Luzerna, Mafra, Matos Costa, Videira, Xanxerê e Porto União fronteira com o Paraná. A repressão foi dirigida pelo $5^{\circ}$ Batalhão de Engenharia de Combate Blindado $5^{\circ} \mathrm{B}$ E CMB BLD. Comandado pelo General de Brigada Dario Coelho. Em abril de 1964, ele ordenou a prisão e indiciou 230 pessoas nas cidades de Porto União, Major Costa, Canoinhas e Irineópolis. Ele indiciou também no inquérito: Leonel Brizola, Getúlio Vargas e Fidel Castro. (COMISSÃO ESTADUAL DA VERDADE PAULO STUART WRIGHT, 2014, p. 60).

Muitos dos presos políticos de 1964 preferiram deixar o caso no anonimato ou no esquecimento - pelo menos até 1998, quando o Estado de Santa Catarina abriu ação de reconhecimento das violações políticas favorecendo a construção do mito de que reinou a "lei" e a "ordem" pelo interior do Brasil durante a ditadura. Nas décadas seguintes, no entanto, muitos casos se tornaram públicos: João Vitelmo Marques, então vereador da cidade de Xanxerê, relatou que ele e mais 110 cidadãos de Xanxerê e Xaxim foram presos entre os dias 4 e 6 de abril de 1964 sob suspeita de integrarem o Grupo dos Onze. No ato da prisão, muitos deles se encontravam trabalhando ou em sua própria residência, como João, que foi levado até o quartel da cidade de Chapecó. Nesta entrevista destacou, ainda, que ficou preso durante dois meses, sofrendo com agressões físicas e psicológicas sendo interrogado sobre a formação do grupo, sobre "causar agitação" entre os trabalhadores e por pertencer ao PTB ligado ao Brizola ${ }^{4}$.

No caso específico da região Oeste, na visão dos militares, houve a adesão de pessoas ao movimento de Brizola. Isso ocasionou prisões, torturas, cassações e perseguições. No caso já mencionado de Sadi de Marco, antes mesmo de ser prefeito e ter seu mandato cassado, permaneceu 24 horas preso nos primeiros dias de abril de 1964. Também, Genir Destri, precisou responder a um Inquérito Policial Militar (SILVA, 2014, p. 63). Um estudo sobre a violação dos direitos humanos em Chapecó durante a ditadura civil-militar demonstra que nos primeiros dias de abril de 1964, a polícia militar realizou em torno de 22 prisões de membros do PTB, sem acusação prévia (HANAUER, 2016, p. 31), incluindo o caso mencionado de Sadi de Marco.

A partir de 1998, um processo indenizatório movido por familiares de vítimas da repressão detalhou, através de depoimentos, como os suspeitos foram tratados pelos militares naquela ocasião. E, por diferentes maneiras, esse processo de perseguição aumentaria ao longo da ditadura civilmilitar, principalmente entre 1964 e 1970, momento em que forças moderadas do MDB - oriundas do PTB, como João Destri - voltam a ter controle sobre o partido. Em nosso argumento, este período entre 1964 e 1970 é o ponto máximo para observar a influência do pensamento de Brizola na região; e, por consequência, a continuidade do processo de violência sobre o PTB inaugurado em 1950 com o linchamento.

Durante o restante da década de 1970, a Aliança Renovadora Nacional (ARENA) - partido de sustentação da ditadura - consolidou seu poder eleitoral até o início da abertura política na década de 1980. Nesse período, a repressão se direcionou mais fortemente aos movimentos sociais.

\section{Notas}

1 A "simples acusação de apoio vermelho à oposição dos udenistas em nível nacional bastava para desqualificar os adversários de pleito". E, conforme demonstra Siqueira, o PTB era mais vulnerável as críticas por estar ligado ao líder Leonel Brizola, do que propriamente o PSD, porém, com o pleito eleitoral se aproximando a UDN buscava apoio do PTB em Chapecó para as eleições de 1955 (SIQUEIRA, 2016, p. 74).

2 Em Passo Fundo, o Comitê Pró-legalidade utilizou-se da sede da Câmara de Vereadores para abrir inscrições para alistamento em defesa da posse de Jango e respeito à Constituição. O Partido Democrático Cristão (PDC), considerado conservador, manifestou apoio ao movimento, além do Centro de Tradições Gaúchas Lalau Miranda e funcionários do Banco do Brasil, que na 
época tinham grande prestígio na comunidade, também aderiram à campanha. As mulheres passo-fundenses, jogadores de várzea, a igrejas cristãs, evangélicas, metodistas e maçons também se organizaram quanto ao movimento. Estima-se que 3 mil pessoas se alistaram em Passo Fundo apoiando o movimento legalista. Em 3 de setembro de 1961, as tropas legalistas saíram da cidade de Cruz Alta, passando por Passo Fundo rumo ao Estado vizinho, Santa Catarina, onde se encontraram com as tropas do I e II Exército (MONTEIRO, 2011, p. 25).

3 A retórica combativa, "aguerrida", em tom de enfrentamento, que se tornou uma das marcas de Brizola, pode ser observada em momentos posteriores da década de 1960. Como exemplo, em 1966 foi organizado o MDB em Chapecó com a presença dos deputados Genir Destri e Paulo Macarini e o vice-governador de Santa Catarina, deputado Francisco Dall'Igna. De acordo com a matéria do Jornal Folha d'Oeste, "um ponto a destacar foi a palavra do deputado Genir Destri”, que "dirigiu severas críticas ao Governo Federal e aos componentes da ARENA". Para o jornal, os elementos dos pronunciamentos combativos estavam presentes: “[...] em seu violento discurso [disse] que a ARENA vem colhendo adeptos através do cabresto, se referindo à fusão dos ex-pessedistas com ex-udenistas", Destri disse "que azeite não se mistura com vinagre, tecendo outros comentários sobre o partido ex-udenista" (FOLHA D’OESTE, 1966).

4 Ver Sicrea Filho, 2011. A título de comparação com casos do Rio Grande do Sul, a história de Marques pode ser comparada à de Dionysio Cerutti, que teria integrado o Grupo dos Onze em Frederico Westphalen, na qual seu filho Ivan Cerutti relata: "Meu pai foi levado preso, a prisão se localizava atrás da prefeitura velha. Todos juntos, inclusive, para fazer as necessidades fisiológicas pelo fato de o recinto ser muito pequeno, enquanto tomavam o depoimento dos outros presos políticos, o castigo para meu pai, foi o de ficar se equilibrando com os pés em cima de dois tijolos dentro do sanitário, chamado de "patente", improvisado durante horas e não poderia se desequilibrar, pois senão cairia nas fezes que ali se depositavam [...] (lágrimas). Emociono-me ao lembrar disso, pois tinha apenas 12 anos, era um garoto. Fui levar alimentação para meu pai e me escorraçaram de dentro da prefeitura velha, fui empurrado, e a marmita que minha mãe tinha preparado caiu no chão. Uma professora passou, me viu e me mandou ir embora, foi um gesto humano, pois viu meu desespero. Quando os presos tomavam banho de sol, pessoas ilustres da comunidade, inclusive compadres do meu pai, passavam e xingavam eles, chamando-os de macacos, pois estavam todos agachados próximos à cerca do pátio da prisão. Quando foi instaurada a revolução de 1964, os sinos da Catedral tocaram, saudando a revolução, numa atitude de concordância e fortalecimento da ditadura que se instalava e para anunciar que o Brasil tinha se livrado dos comunistas. Após anos de ditadura, quanto da reabertura democrática, fui até a Catedral, para tocar os sinos pela volta da democracia; porém, fui impedido. Têm pessoas vivas que podem confirmar isso" (SZATKOSKI, 2003, p. 111).

\section{Referências}

ALVES, Maria Helena Moreira. Estado e Oposição no Brasil 1964-1984. Bauru: EDUSC, 2005.

BRANDALISE, Carla; HARRES, Marluza Marques. Comandos Nacionalistas no interior do Rio Grande do Sul: Notas preliminares. Historiae, v. 5, n. 2, p. 67-86, 2014.

BRANDT, Marlon; SILVA, Naiara Sampaio. A coleta da erva-mate pela população cabocla do Vale do Rio do Peixe e Oeste de Santa Catarina: Apropriação privada da terra e rupturas (décadas de 1900-1940). Soc. \& Nat. Uberlândia, v. 26, n. 3, p. 459-469, 2014.

BRASIL. Lei no 9.455, de 7 de abril de 1997. Define os crimes de tortura e dá outras providências. Disponível em: http://www.planalto.gov.br/ ccivil_03/leis/L9455.htm. Acesso em: 11 maio 2017.

CARVALHO, José Murilo de. Chumbo grosso: assassinato e tortura eram práticas comuns durante a ditadura de Getúlio Vargas. Revista de História, Rio de Janeiro, v. 59, [s. p.], ago. 2010.

COIMBRA, Cecilia Maria Bouças. Tortura ontem e hoje: resgatando uma certa história. Psicologia em estudo, v. 6, n. 2, p.11-19, 2001.

\section{COMISSÃO ESTADUAL DA VERDADE PAULO STUART WRIGHT. Relatório Final.} Florianópolis: ALESC, 2014. Disponível em: http://www.documentosrevelados.com.br/wpcontent/uploads/2016/04/relatorio_final_-_ novembro_-_20-11-14_1_2.pdf p. 31. Acesso em: 10 nov. 2018.

CRUZ, João Batista Carvalho da. Da formação ao desafio das urnas: O PTB e seus adversários nas eleições estaduais de 1947 no Rio Grande do Sul. 2010. 170 f. Tese (Doutorado em História) - Programa de Pós-Graduação em História, Universidade do Vale do Rio dos Sinos, São Leopoldo, 2010. 
DESTRI, Genir. Entrevista concedida à Claiton Marcio da Silva. Chapecó, 1999.

GRILL, Igor Gastal. Bases sociais e intérpretes da "Tradição Trabalhista" do Rio Grande do Sul. Revista de Ciências Sociais, v. 48, n. 3, p. 525-557, 2005.

HANAUER, Luiz Fernando Perondi. A inobservância dos direitos humanos na cidade de Chapecó no contexto da ditadura militar: análise de depoimentos judiciais de presos políticos. 2016. 31 f. Trabalho de Conclusão de Curso (Licenciatura em História) - Universidade Federal da Fronteira Sul, Chapecó, 2016.

HASS, Monica. Os partidos políticos e a elite chapecoense: um estudo de poder local (19451965). Chapecó: Argos, 2001.

HASS, Monica. O linchamento que muitos querem esquecer: Chapecó, 1950-1956. 2. ed. rev. e ampl. Chapecó: Argos, 2007.

JORNAL FOLHA DO OESTE. Organizado o MDB em Chapecó, Dall-Igna presente. Chapecó, 2 de jul. 1966.

MARCONDES FILHO, Ciro. Violência fundadora e violência reativa na cultura brasileira. São Paulo em perspectiva, v. 15, n. 2, p. 20-27, 2001.

MONTEIRO, Paulo. A campanha da legalidade em Passo Fundo. Passo Fundo: Projeto Passo Fundo, 2011.

MOTTA, Rodrigo Patto Sá. Em Guarda contra o Perigo Vermelho: o Anticomunismo no Brasil (1917-1964). 2000. 315 f. Tese (Doutorado em História) - Programa de Pós-Graduação em História, Universidade de São Paulo, São Paulo, 2000 .

MUCHEMBLED, Robert. História da violência. 1. ed. Rio de Janeiro: Forense, 2012.
RIGHI, Graziane. Grupos dos Onze: a tentativa de resistência. In: SEMINÁRIO INTERNACIONAL HISTÓRIA DO TEMPO PRESENTE, 2, 13-15 out. 2014, Florianópolis. Anais... Florianópolis: UDESC, 2014. p. 1-16.

SICREA FILHO, Romeu. Xanxerense é indenizado por tortura durante a ditadura militar. 2011. Folha Regional. Disponível em: http://www.redeprincesa. com.br/index.php/desc_noticia/xanxerense_e_ indenizado_por_tortura_durante_a_ditadura_ militar/. Acesso em: 19 maio 2017.

SILVA, Claiton Marcio da. Dos braços do povo à espada dos militares: os anos de chumbo na Fronteira Sul (1964-1970). Florianópolis: Pandion, 2014.

SIQUEIRA, Gustavo Henrique de. Os donos do "celeiro do progresso": Redes sociais e Política (Chapecó, 1956-1977). 2016. 289 f. Dissertação (Mestrado em História) - Universidade do Estado de Santa Catarina (UDESC), Florianópolis, 2016.

SZATKOSKI, Elenice. Os grupos dos Onze: Política, poder e repressão na região do Médio Alto Uruguai- RS 1947/1968. 2003. 191 f. Dissertação (Mestrado em História) - Programa de PósGraduação em História, Universidade de Passo Fundo, Passo Fundo, 2003.

SZATKOSKI, Elenice. O jornal Panfleto e a construção do brizolismo. 2008. 191 f. Tese (Doutorado em História) - Programa de PósGraduação em História, Pontifícia Universidade Católica do Rio Grande do Sul, Porto Alegre, 2008.

ZONATTO, Rejane. O grupo dos onze no Brasil e no Vale do Taquari. 2010. 99 f. Monografia (Graduação em História) - Universidade do Vale do Taquari, Lageado, 2010. 